\title{
Casper Hendrik Rautenbach: 'Singewing aan dink al hoe meer in verband met doen'
}

\author{
HT van Deventer
}

\begin{abstract}
Casper Hendrik Rautenbach: 'Deeds, more than ideas, make life meaningful'

Professor Casper Hendrik Rautenbach was born on 6th of March 1902 in Zeerust in the Western Transvaal, RSA, where he matriculated at the Zeerust Public School at the end of 1918. In June 1923 he was awarded the MA degree in Philosophy and at the end of the same year the BD degree in Theology. In 1932 he completed his thesis, titled 'Sedelike Keuring (Kritiek oor McDougall)'. After serving as clergyman in the Nederduitsch Hervormde Kerk van Afrika, and as lecturer in Philosophy and Christian Ethics, he was promoted to Rector of the University of Pretoria, an office which he held from the 9th of April 1948 until the 30th of June 1970. Professor Rautenbach is respected as an outstanding academic and leading churchman. He achieved outstanding results in the educational field especially by playing an active role in the formulation of the Education Policy Act (Act 39 of 1967).
\end{abstract}

Geskrewe erkenning aan en waardering vir prof $\mathrm{CH}$ Rautenbach deur vriende en kollegas laat val die soeklig op hom as mens, as vriend en kollega, as filosoof en kerkman, as opvoedkundige en as rektor. Deurgaans en in al die onderskeie verbande is die getuienis uiters positief en opwindend. Ten spyte van sy klein gestalte word hy monumentaal staangemaak as een van die grootstes onder die groot mense. Afwisselend word hy geroem vir sy besondere intellek en sy beskeidenheid, sy deernis en sy vasberadenheid, sy verbondenheid aan die verlede en sy toekomsvisie.

Tussen al hierdie en baie ander stemme van respek en eerbetoning, wil die skrywer van hierdie inleidingsartikel tot die $\mathrm{CH}$ Rautenbachhuldigingsnommer ook graag uit eie belewenis en kennis 'n stem laat hoor. Inderdaad is dit ' $n$ voorreg van groot omvang en betekenis om te mag skryf oor ' $n$ man wat soos alle ander geskape mense nie volmaak is nie, maar tog begenadig is om die tyd voortdurend uit te koop en binne 
menslike vermoëns en beperkings 'n vol en ryk lewe te kon lei en steeds te lei.

\section{CH RAUTENBACH: DIE MENS}

Gebore op 6 Maart 1902 op Zeerust in Wes Transvaal, is hy van die sesde geslag Rautenbachs na die aankoms in 1757 in Suid-Afrika van Georg Friedrich Rautenbach, stamvader en Duitse huursoldaat in diens van die VOC. Sy skoolonderrig ontvang hy deur middel van die Engelse taalmedium aan die 'Zeerust Public School'. Sy vader het vir hom op twaalfjarige ouderdom 'n loopbaan in die Posterye as bode beplan, mede daarom dat daar 'n pensioen aan die einde sou wees. Daar is waarskynlik drie redes waarom hy sy vader se keuse omseil het ter wille van 'n akademiese loopbaan. Uit sy eie getuienis word aangevoer sy onwilligheid om sy brood op 'n fiets se saal te verdien maar hoofsaaklik sy moeder se waardering vir voortgesette onderwys. Daarby kan ons egter sonder vrees vir teenspraak byvoeg sy vurige idealisme sowel as sy strewe na diensvaardigheid op ' $n$ ander terrein van medemenslikheid. As gevolg van merkwaardige selfdissipline en dryfkrag, slaag hy matriek aan die einde van 1918 met eerste klas. Matriek, afgelei van die Latynse matrix, of vroulike baarmoeder, beteken telkens geboortegewing na 'n skoolloopbaan aan jong, selfstandige denkers en werkers. Met die naelstring van verbinding aan die beskermende omgewing van die skool afgesny, behoort die suksesvolle kandidaat uit eie oortuiging en aangevuur deur eie ideale die toekoms in te stap. Die jong Rautenbach het sy toekoms op 3 Maart 1919 as student aan die destydse Transvaalse Universiteitskollege betree. Aanvanklik was sy bedoeling om met ' $n$ merietebeurs in sy sak hom vir die onderwys te bekwaam. 'n Ewige waarheid het egter ook hier gegeld, naamlik dat die mens wik maar God beskik. Einde 1923 behaal hy die graad BD nadat hy in 1921 op negentienjarige leeftyd BA met lof geslaag het en in Junie 1923 ook die MA in Wysbegeerte met lof afgehandel het. Vir die predikantsamp was hy vir die eertydse kerkvaders egter te jonk en vanweë 'n kerkbesluit in diervoege moes hy noodgedwonge begin om Wysbegeerte aan die TUK te doseer. In 1924 is hierdie doseerwerk verder aangevul met 'n opdrag tot oordrag van Sielkunde.

Aan die einde van 1926 kon hy mèt die nodige kennis en lewensjare die amptelike terrein van die kerk betree en wel as predikant van die Gemeente Bronkhorstspruit en vanaf 1930 as medeleraar van die gemeente in Noordelike Pretoria met 'n wyduitgestrekte bedienings- 
gebied. Intussen het hy hoofsaaklik op eie inisiatief, maar tegelyk ywerig, aan sy doktorsgraad gewerk wat hy in 1932 behaal het met 'n proefskrif wat in 1939 in druk verskyn het met die titel: 'Sedelike keuring (Kritiek oor McDougall)'.

Vanaf 1934 tot einde 1938 is hy deeltydse lektor in Wysbegeerte aan die Universiteit van Pretoria en begin 1939 word hy voltydse professor in dieselfde departement terwyl hy in verskillende hoedanighede ook doseerpligte in Sielkunde en Opvoedkunde vervul. In die Fakulteit Teologie het hy 'n eie bydrae gemaak deur middel van lesings in die Christelike Etiek.

Teen sy eie verwagting in word hy op 9 April 1948 as Rektor van UP aangestel, die begin van ' $n$ tydperk van meer as twee en twintig jaar se doelgerigte en daadkragtige beleidbepaling en leidinggewing aan 'n tersiêre onderwysinrigting wat gedurende daardie jare op alle terreine gegroei en gebloei het. Dat almal nie ewe ingenome met sy aanstelling was nie, is te begrype. Waar is daar ooit eenstemmigheid tussen mense, veral ook in tye van radikale politieke veranderinge? Selfs die eerste predikantevergadering na sy aanstelling se notule lewer geen bewys van gelukwensing of erkenning aan ' $n$ man wat op eie kerklike en kollegiale gebied hoogstaande gepresteer het nie. Desnieteenstaande het hy daarin geslaag om met groot onderskeiding uiting te gee aan die universiteitsrektorskap met sy eis tot daadwerklikheid, sy betrokkenheid en sy gevolglike ampte, dienste, pligte ensovoorts. Vandag nog herinner menige oudstudent uit daardie era hom 'prof Rauties' se skerpsinnigheid, pragtige humor, maar ook sy beslistheid en onbuigsaamheid waar dit om beginselsake gaan.

Op 30 Junie 1970 tree hy uit die diens van die Universiteit, 'uit die deelnemer na die toeskouers se sfeer'. Terselfdertyd bring sy uittrede vir hom die geleentheid vir stelselmatige voortgesette verdieping in die ineengestrengelde belangstellingsterreine rondom die vraag in Psalm 8: 5: 'Wat is die mens?' Maar nou was dit oorwegend vanuit die invalshoek van die diepste grondslae van die nasionale onderwysontplooiing soos dit algaande beslag gekry het tussen 1962 en 1971. Die Teologie het intussen weer vir hom 'n saak van groot erns geword. Voltydse leeswerk oor dit wat op teologiese werf gebeur het en aan die gebeur is, het meegebring dat die kerkman wat 'tydelik aan die Universiteit geleen is' weer sy verskyning in die Algemene Kerkvergadering, die Predikantevergadering en ook die Raad vir Opvoeding en Onderwys gemaak het. Optredes tydens sodanige geleenthede het menige predikant (oud en jonk) laat sidder voor die aanslag van formidabele intellek, 
kennis en insig. Vir baie is en bly prof Rautenbach 'n bron van inspirasie en aanmoediging om steeds studerend met die teologie besig te bly.

Iemand wat 'n baie besondere rol in sy lewe gespeel het, soos dit trouens ook hoort in enige man se lewe, is sy eggenote mev $\mathrm{CW}$ Rautenbach, wat as 'n nooi Oosthuizen in sy lewe gekom het en met wie hy op 9 April 1927 getroud is. Van haar skryf hy: 'Sy het my van 'n dreigende swewende filosofiese eksistensie in hoë regioene na die essensie van vaste moeder aarde teruggeroep, van bespiegeling na daadwerklikheid, teorie na praktyk, uit die studeerkamer na voller lewe gelei, saam gereis, met heelwat geduld en groot moed bygestaan.' Uit hierdie gelukkige en voorbeeldige huwelik is drie kinders gebore: Lukas Johannes (1929), Martha Wilhelmina (1932), Nicolaas Oosthuizen (1938). Vandag is daar reeds ses kleinseuns, vier kleindogters met een agterkleinseun en twee agterkleindogters.

\section{CH RAUTENBACH: WETENSKAPPER VAN FORMAAT}

Prof Rautenbach se wetenskaplike denke en werk toon 'n merkwaardige veelsydigheid. Eenstemmigheid bestaan egter met betrekking tot hoofsaaklik drie hoofrigtings: Filosofie, Teologie en Opvoedkunde (meer spesifiek 'onderwyskunde'). Nadere beskouing van talle geskrifte en persoonlike waarneming uit gesprekke dui onteenseglik op teologiese voorkeur. Die Woord van God bly vir hom die grondslag en bron van alle waarheid. Vir 'n waardering van prof Rautenbach as filosoof word, by gebrek aan eie vermoë tot gesonde oordeel, prof PS Dreyer oorsigtelik aan die woord gestel.

Volgens hom is die beste uiteensetting van prof Rautenbach se beskouing oor die Wysbegeerte te vind in ' $n$ artikel oor ' $W y$ sbegeerte en geloof'. Hiervolgens is prof Rautenbach daarvan oortuig dat die Wysbegeerte tot die kultuurgebied van die wetenskap behoort en wel tot die orde van die ervaringswetenskappe, 'anders is dit vrugtelose hersengimnastiek en ydel tydverkwisting'. Ervaringswetenskap is wat die nadenkende verstand verkry deur ordening, bewerking en aanvulling van wat die ondervinding as feite leer ken, beide deur wat ons waarneem en wat ons beleef. Met betrekking tot die ervaringswetenskap as sodanig formuleer hy dit so dat dit die taak 'van die ervaringswetenskap (is) om 'n oorsig oor ' $n$ insig in die betrokke feite te gee. Ons kan ook sê: dis die sin van die ervaringswetenskap om 'n beskrywing en verklaring van die ervaringsfeite tot stand te laat kom'. Breedvoeri- 
ger gestel, beteken dit vir hom dat elke ervaringswetenskap die taak het om:

1. Sy eie ondersoekingsterrein af te baken onder die ervaringsverskynsels;

2. Sy eie navorsingsmetodes te kies met inagneming van

(a) die aard en bestaanswyse van sy voorwerp van ondersoek;

(b) die oogmerk van die navorsing; en

3. Selfbeperkings op te lê ten opsigte van wysgerige vooropstellings en voorskrifte, dit wil sê vooropstellings en voorskrifte wat nie spruit uit die feite self nie, maar wat op daardie feite toegepas word kragtens die ondersoeker se verstandseise.

Hoewel prof Rautenbach baie klem op die feite van die ervaringsgegewens lê, is hy egter geen empiris wat die totaal van ons kennis in al sy aspekte na die ervaring wil terugvoer nie. Heeltemal in die Kantiaanse styl is wetenskap 'n aktiwiteit van die wetenskaplike en die inisiatief lê by die wetenskaplike. Soos Kant dit self uitdruk: ons leer van die natuur, maar nie soos ' $n$ leerling van sy onderwyser leer nie, maar soos 'n regter van die getuies leer.

Vir prof Rautenbach is die Wysbegeerte inderdaad ervaringswetenskap in die sin dat dit alleen met die feite wat aan ons gegee is, kan werk en met die redelike vermoëns van die mens. Anders gestel: die Wysbegeerte kan alleen op wetenskaplikheid aanspraak maak indien dit beantwoord aan die eise van die logika. Die Wysbegeerte is ervaringswetenskap naas ander ervaringswetenskappe in die sin dat dit sy studie-objek en studieterrein in sy eie reg het, en dit volgens sy metodes bearbei. Die studieterrein van die Wysbegeerte bestaan uit die volgende hoofgebiede:

* Die gebied van die werklikheidsprobleme

* Die gebied van die waardeprobleme

* Die gebied van die kennisprobleme

* Die gebied van die antropologiese gebeure.

Prof Rautenbach het verder in talle van sy geskrifte geworstel met die probleem van die verhouding tussen wetenskap - by uitstek Wysbegeerte - en geloof, een van die neteligste probleme van die Wysbegeerte en van die Teologie sedert die tweede eeu van ons jaartelling. Die botsing tussen Wysbegeerte en geloof ontstaan omdat albei hulle van oudsher besig hou met wêreldbeskouing en lewensopvatting, met die 
waardevolle en die norme, met die sin van die lewe en die bestemming van die geskiedenis.

Geloof (ons praat hier saam met prof Rautenbach alleen van die Christelike geloof) is altyd Skriftuurlik gebonde geloof en dit hoort tot sy wese om die mens in sy geheel op te eis vir gehoorsaamheid aan die voorskrifte van God, soos geopenbaar in die Bybel. Van oudsher was daar filosowe wat dit as hulle goeie reg opgeëis het om self die wese en oorsprong van die syn te bepaal, asook die voorskrifte vir die behoorlike lewensvoering.

Die wyse waarop prof Rautenbach die probleem behandel, is om iedere keer die wese van wetenskap aan te dui, daarna die wese van geloof en dan die twee teen mekaar af te grens. Oor wetenskap is vir die oomblik genoeg gesê.

Wat geloof betref, sluit prof Rautenbach aan by Hebreërs 11: 1, 2 en 3 en by die Heidelbergse Kategismus, vraag 21, om te beklemtoon dat die geloof ' $n$ bewys is van die dinge wat ons nie sien nie, 'n vertroue op die dinge wat ons hoop. Hier is daar sprake van kennis en bewys begrippe wat in die wetenskap 'n uiters belangrike rol speel. Hierdie kennis en bewys is egter heeltemal van ' $n$ ander orde as die wetenskaplike, omdat die geloof getuienis lewer op grond van die Bybel en dié getuienis uitdruk in die belydenisskrifte. Die kennis en bewys waarvan daar min sprake is, berus in die laaste instansie op die handelinge van God wat Hom in die skepping, maar by uitstek in die Bybel, openbaar.

Die verhouding tussen wysbegeerte en geloof kan alleen 'n gesonde en korrekte verhouding wees wanneer albei uitgaan van die gedagte van begrensdheid. Kant het vir ons onteenseglik die grense van die wetenskap aangetoon: as wetenskaplike kennis kan alleen geld wat op die feite en die logika berus. Wie een van die twee oorskry - dit wil sê verder gaan as die ervaringsgegewens of die geldigheid van die rede verder uitbrei as wat geverifieer kan word - het die grense van wetenskap oortree en is nie meer met wetenskap besig nie. Ons kennis van God is 'n saak van openbaring en geloof en val nie binne die moontlikhede van menslike ervaring en denke nie. Dit is die gebied van die supra-teoretiese.

Aan die ander kant is die Bybel geen wetenskaplike handboek of versameling onbetwyfelbare uitsprake oor allerlei wetenskaplike aangeleenthede nie. Wanneer die Bybel só gebruik word, val die Bybelse uitsprake binne die sfeer van die wetenskap. Dan moet die Bybelse uitspraak voor die regbank van die rede gedaag word en moet dit die 
toets van verifikasie aan die hand van feitlike gegewens en logiese steekhoudendheid kan deurstaan.

Dit beteken egter nie dat die twee niks met mekaar te doen het nie. Juis Kant het aangetoon dat ons sedelike lewe onmoontlik is sonder die aanvaarding van God en onsterflikheid. Dit is egter aanvaarding, geloof of, in Kant se terminologie, postulate wat ons noodsaaklik moet aanvaar, maar wat hoegenaamd nie 'n wetenskaplike aangeleentheid is nie. Heymans het aangetoon dat dit die diepste behoefte by die mens is om te weet dat daar bepaling van sy lewenslot is. Dit is egter die verste wat die filosofie kan gaan. Wat die postulate is wat ons moet aanvaar, wat of wie die hoogste magte is, kan die filosofie nie sê nie. Daaroor praat die teoloog op grond van die openbaring van God.

\section{CH RAUTENBACH: ONDERWYSKUNDIGE}

Prof Rautenbach se benadering ten opsigte van die onderwys is ten diepste begrond in sy oortuiging dat Christenwees in die wêreld ook Christenwees in die openbare onderwyswêreld beteken.

Dit geld ook vir die kerkwees in die wêreld (apostolaat). Vanuit hierdie perspektief kon hy as eerste voorsitter van die Nasionale Adviserende Onderwysraad sedert 1963 primêre verantwoordelikheid aanvaar vir die formulering van die RSA se hoofonderwysbeleidswet (Wet 39 van 1967), aangevul deur Wysigingswet 73 van 1969 met betrekking tot onderwysersopleiding. Hierdie wette wat huidig nog feitlik onveranderd gehandhaaf bly, is duidelik bewys van sy besondere visie en kundigheid op onderwysgebied. Deur sy bemiddeling is toegesien dat ons hele publieke onderwysstelsel deur owerheidsverordening in die Bybel gewortel is. Sy uitgangspunt is soos volg geformuleer:

Die Godskennis (openbaring), voorhande in daar die bundel heilige boeke - as geloofsgetuienis bely en afgelê in die Naam van God deur profete, evangeliste en apostels - bied breë aansluitings vir die sekulêre) opvoedende onderwys. Daarin is ook invalshoeke vir 'n mensopvatting insluitend kind en jeugdige, onvolwassenheid en volwassemaking (opvoeding, vorming) tot verantwoordelike bestaan.

Prof Rautenbach het in die Nederduitsch Hervormde Kerk oor baie dekades heen feitlik man-alleen begronding en toeligting, formulering 
en motivering verskaf vir 'n onderwysbeleid wat die toets van die tyd tot dusver kon deurstaan. Sonder om die besondere bydraes van ander teoloë en opvoedkundiges binne eie kerkgeledere te ontken, geld sonder vrees vir teenspraak die waarheid dat prof Rautenbach by uitnemendheid die leidende rol gespeel het. Dit het onder andere tot gevolg gehad dat in 'n gewaardeerde resensie van 'n proefskrif waarin die begronding van die Nederduitsch Hervormde Kerk se onderwysbeleid tussen 1902 en 1985 nagevors is, die volgende stelling gemaak word: 'Soms kry'n mens net die gevoel dat die proefskrif se Rautenbach-sentrisme neig na 'n Rautenbach-eensydigheid.' Die moontlikheid van so 'n neiging is waarskynlik, aangesien die resensent self wys op die 'reusebydrae (wat) Rautenbach vanuit die Hervormde kerk op die gebied van die onderwys en opvoeding van ons land gemaak het'. Genoemde moontlike eensydigheid is eintlik meer die gevolg van té veel kerklui se traagheid om werklik indringend met die problematiek rondom onderwys en opvoeding besig te raak en by te dra tot die soeke na antwoorde en oplossings binne die multikultureel-saamgestelde bevolking. Hierdie traagheid geld vir verlede en hede en prof Rautenbach se bemoeienis (ook op vyf en tagtigjarige leeftyd) is uiters voorbeeldig en aanmoedigend.

Wanneer prof Rautenbach as onderwysman gehuldig word, dan tree hy na vore as student, akademiese dosent, rektor, navorser, leier en voorsitter van té veel rade, kommissies en ander liggame om op te noem. Van groot belang is naas die reeds genoemde Nasionale Adviserende Onderwysraad, die Nasionale Raad vir Sosiale Navorsing, Wetenskaplike Adviesraad, Interkerklike Kommissie vir Opvoeding en Onderwys, en die Nederduitsch Hervormde Kerk se Raad vir Opvoeding en Onderwys.

Onderwysbelangstelling en geskrifte het prof Rautenbach in 1965 in die getuiebank van die Wêreldhof - "'n gevorderde skool in mensekennis en manipulering' - laat beland. Adv RF (Pik) Botha, destyds deel van die regspan vir die Suid-Afrikaanse Regering in die wêreldhofsaak oor Suidwes-Afrika, skryf soos volg:

Ons was trots op al ons getuies - veral op ons medevolksgenote. In prof Rautenbach se geval was daar, wat my persoonlik betref, belangrike bykomende redes om ekstra trots te wees - nie net was hy my universiteitshoof nie, maar ons mense het van dieselfde geweste gekom - die noord-weste van Transvaal. Dit was 'n onvergeetlike voorreg om hom te kon hoor en sien optree in Den Haag waar hy dit sterker as ooit by my tuisgebring het dat behoud 
van die eie die onverbiddelike eis stel dat daar deur die eie gepresteer moet word.

\section{PROF RAUTENBACH SE GESKRIFTE}

Dit is onmoontlik om al prof Rautenbach se geskrifte wat bestaan uit publikasies, artikels, geskrewe toesprake, kommentare, ensovoorts te lys. In totaal is daar oor die driehonderd daarvan. Van sy werk op skrif sê hyself:

Skrywer maak hom wys dat 'n latente patroon, wat hom toegeval het, tog deur sy begenadigde werkies en pretensielose skryfwerk skemer. Of is die patroon-mening net nuttige inbeelding en opgeefsel en verder gefingeerde sleutel vir die potensiële leser? Dáár gaan die geskrifte oor:

\section{SINGEWING AAN DINK AL HOE MEER IN VERBAND MET DOEN}

Die volgende word wel genoem:

Dreyer, PS 1975: Prof dr CH Rautenbach: Versamelde geskrifte. Pretoria: HAUM.

Daarin verskyn:

\section{Deel I 1926-1948}

Genl Smuts en die wysbegeerte - nuwe opvatting van die wêreld Gedagtes oor 'n Christelike wêreldbeskouing

Determinisme en die Mikro-Fisika

Sedelike keuring

Ons lewensopvatting

Rede gehou by geleentheid van die herdenkigsdag van die Universiteit van Pretoria op 16 September 1942

Wysbegeerte en geloof

\section{Deel II 1948-1970}

\section{Algemeen}

Die nuwe voorkoms van die middelbare onderwys in Transvaal 
Bakens langs die weg van Afrikaanswording

Vordering van eerstejaars

Skool en universiteit

Universitêre onderwys in Pretoria

Die onderwysorganisasie van ' $n$ universiteit

Inleiding tot die Ingenieurswese

Ter begeleiding

Hou die deure oop

Ten geleide: Verslag studentevordering 30 September 1975

Die Universiteit en sy oud-studente

Beantwoord SA universiteite aan hul doelstelling

Beoordeling van ons universiteite

Hier word tradisie gou gevestig

Die brug tussen die hoërskool en univèrsiteit

Hiervandaan verder

Waarheen ons universiteite?

Doelbereiking verskaf vreugde

Ope gesprek oor beslote universiteite

'n Didaktiese fragment

Nuwe onderwysgeluide in die nuwe Afrika

Aide-memoire oor toewysing van sekondêre onderwys

Aide-memoire

Die waarheid en leuen van die Kommunisme

Onderwysbeplanning Syfers en Statistieke

Belegging in universiteite

'n Ou geskiedenis

Politiekery deur universiteitsdosente

Die toekoms

Geskeie universitêre ontwikkelingimperatief van die geskiedenis in wording

Reserwe aan potensiële universiteitstudente

Aanpassing van die hoërskoolleerling by die universiteit

Die universiteit: Sy oorsprong, aard en funksies

Die student in ' $n$ veranderde wêreld

Het ons onderwys tred gehou?

Die staat en universiteit

Die uitdaging van verandering - Die opvoeding van die verpleegster

No easy way

Changes in education policy

Universiteit en getal 
Rektor oor dr Verwoerd en die jeug

'n Nuwe plan vir die opleiding van onderwysers

Leer uit die verlede

Memorandum: Kommissie van Ondersoek na die Universiteitswese

Toespraak gelewer deur die rektor by geleentheid van Ouerdag op 2 Februarie 1970

Beginsel en slagkreet

A decade of university expansion

\section{Deel III 1970-1973}

Die geloofsgemeenskap en die skoolonderwys

Tot hiertoe en verder

Die toekoms van onderwysersopleiding en onderwysersopleiding van die toekoms 1

Gewetensklousule bly twisappel in nasionale onderwys

Nasionale onderwysopleiding. Die Bybel op universiteit - ja, maar hoe? 'n Voorwoord

Vyftig jaar byderwetse Bybelwetenskap

'n Eietydse nasionale kultuurprestasie

Verbande en perspektiewe. Vier en dertig artikels, in Die Hervormer. Vanaf Maart 1975.

Onderwys: Gegrondves op die Bybel. Agt artikels, in Die Hervormer se Nuusbrief, 6 November 1983. 